RESEARCH AND PRACTICE

\title{
A review of community-based participatory research studies to promote physical activity among African Americans
}

\author{
Steven S. Coughlin, $\mathrm{PhD}^{1,2}$ and Selina A. Smith, $\mathrm{PhD}, \mathrm{MDiv}^{3}$
}

${ }^{1}$ Department of Community Health and Sustainability, Division of Public Health, University of Massachusetts, Lowell, MA; ${ }^{2}$ Department of Epidemiology, Rollins School of Public Health, Emory University, Atlanta, GA; ${ }^{3}$ Institute of Public and Preventive Health, Augusta University, Augusta, GA

\begin{abstract}
Background: As part of the planning process for new research, the literature on community-based participatory research (CBPR) approaches for promoting physical activity in African American communities was systematically reviewed.
\end{abstract}

Methods: Studies published through October 31, 2015 that employed CBPR methods were identified using PubMed and CINAHL databases and MeSH terms and keyword searches.

Results: A total of 15 studies met the search criteria. One focused on CBPR and physical activity among African American school children and adolescents, 13 on adults, and one on both children and adults. Seven studies employed CBPR methods to promote physical activity in church settings. Eight of the studies had a pre-/post-test design, three had a quasiexperimental design, three had a randomized controlled design, and one was a case study.

Conclusions: Additional CBPR studies and faith-based interventions are needed to identify effective ways to promote physical activity in African American communities to address health disparities. Of particular interest are those that have an adequate sample size and a rigorous design, to overcome limitations of previous studies.

Key Words: African Americans, community-based participatory research, physical activity

\section{INTRODUCTION}

Physical inactivity contributes to disparities in over-weight and obesity, cancer, and cardiometabolic diseases (Dietz, W. 2015; Kumanyika, S, et al. 2014). Along with maintenance of normal weight, consumption of healthy food, and avoiding tobacco use and heavy alcohol consumption, physical activity contributes to individual health and wellbeing (Sallis, J \& Glanz, K. 2009; Sallis, J, et al. 2006). However, $39.5 \%$ of African American adolescents are overweight or obese and many school-aged children, adolescents, and adults do not meet the national guidelines for engaging in regular physical activity (Ogden, C, et al. 2010; Nader, P, et al. 2008). The Healthy People 2020 Guideline for Physical Activity aims to increase the proportion of youth and adults who meet current federal guidelines for aerobic physical activity (HHS). Over the past decade, a rich literature has developed on community-based participatory research (CBPR) approaches for promoting physical activity in African American communities. Many of these CBPR studies have used faith-based interventions involving people identified through church congregations.

As part of the planning process for CBPR studies on encouraging physical activity among African Americans in Georgia and other states with sizeable African American populations, the published literature on this topic was reviewed. The goals were to examine the effectiveness of
CBPR in increasing physical activity among African Americans and to identify recent trends and developments in CBPR relating to promotion of physical activity in this population, including refinements and innovations in quantitative research methods, frameworks, and educational interventions.

\section{METHODS}

The present review is based upon bibliographic searches in PubMed and CINAHL with relevant search terms. Articles published in English through October 31, 2015 were identified using the following MeSH search terms and Boolean algebra commands: (((community-based participatory research) or (community-based research) or (community-based study) or (action research)) AND (physical activity) AND (African Americans)). Although the search criteria did not specify a begin date, the earliest article that met the search criteria was published in 1989. The searches were not limited to words appearing in the titles of articles. Studies that focused on patients with chronic diseases other than obesity were excluded. Information obtained from bibliographic searches (title and topic of article, information in abstract, geographic locality of a study, and key words) was used to determine whether to retain each article. In addition, reports included in Cochrane reviews were identified (http://community.cochrane.org/cochrane-reviews). The references in reports and review articles were also 
reviewed (8-11). As detailed in Figure 1, 290 citations were found. After screening the abstracts or full texts of these articles, 15 CBPR studies on promoting physical activity among African Americans were identified, all of which were conducted in the U.S. The two eligible studies identified in the CINAHL search overlapped with those identified in the PubMed search (Figure 1). The excluded citations included studies that focused on patients with diabetes, coronary heart disease, and other chronic diseases other than obesity; clinical research studies conducted in hospital and clinic settings; and randomized controlled trials that did not follow CBPR principles (for example, there was no community advisory committee and no members of the target communities were involved in the planning and conduct of the study). The present review extends upon the work of earlier authors by including studies in the past few years (along with earlier studies) and by focusing specifically on CBPR studies involving African Americans. This review article does not contain any studies with human participants performed by the authors and therefore was not subject to institutional review board review.

Figure 1. Summary of search and exclusion process for identified studies

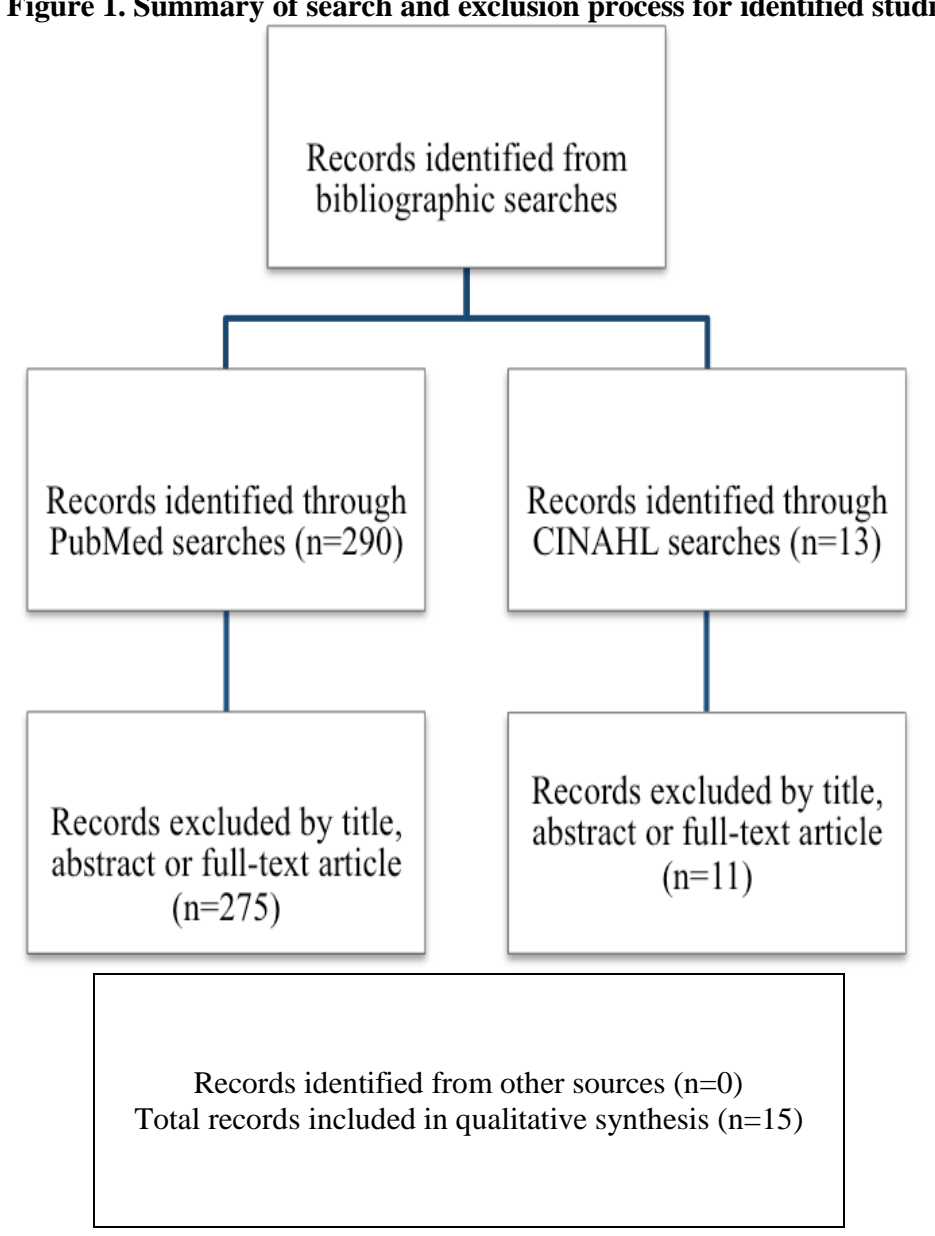

\section{RESULTS}

Of the 15 studies that met the inclusion criteria, one focused on school children and adolescents; the remainder focused on adults $(\mathrm{n}=13)$ or on both children and adults $(n=1)$ (Table 1). Seven studies employed CBPR methods to address physical activity in church congregations or other faith communities. Eight had a pre-/post-test design, three had a quasi-experimental design, three had a randomized controlled design, and one was a case study.

Choudhry et al. conducted a pilot study involving 40 African American children aged 5-12 years who were attending after-school care on Chicago's South Side. The physical activity and nutrition intervention followed CBPR principles and had multiple components (environmental change, nutrition and physical activity education, and outreach by parents). Post-intervention, mean body mass index (BMI) $\mathrm{z}$ scores decreased from 1.05 to 0.81 $(\mathrm{P}<0.001)$. Girls decreased their combined prevalence of overweight/obesity from $52 \%$ to $46 \%$. Among boys, however, the prevalence of overweight/obesity did not change.

Cowart, et al. (2010) performed a pre-post pilot test of a 12week nutrition education and exercise-fitness program among adult members of six churches in Syracuse, NY. Although only 11 of the 22 post-pilot surveys could be linked to earlier assessments, a comparison of assessment data with feedback from those attending 3 to 12 pilot program sessions suggested a pattern of beneficial changes in nutrition and exercise habits. 
Dodani and Fields (2010) conducted a feasibility study of a spiritually-based lifestyle modification program (diet, nutrition, physical activity, and weight control) for diabetes prevention. The participants included 40 adult members of a church in Evans County, Georgia who were overweight, obese, or morbidly obese. Of the 35 participants who attended at least 10 sessions and provided information required for the study, $48 \%$ lost at least $5 \%$ of their baseline weight, $26 \%$ lost $7 \%$ or more, and $14 \%$ lost more than $10 \%$.

Table 1. CBPR studies on physical activity among African Americans

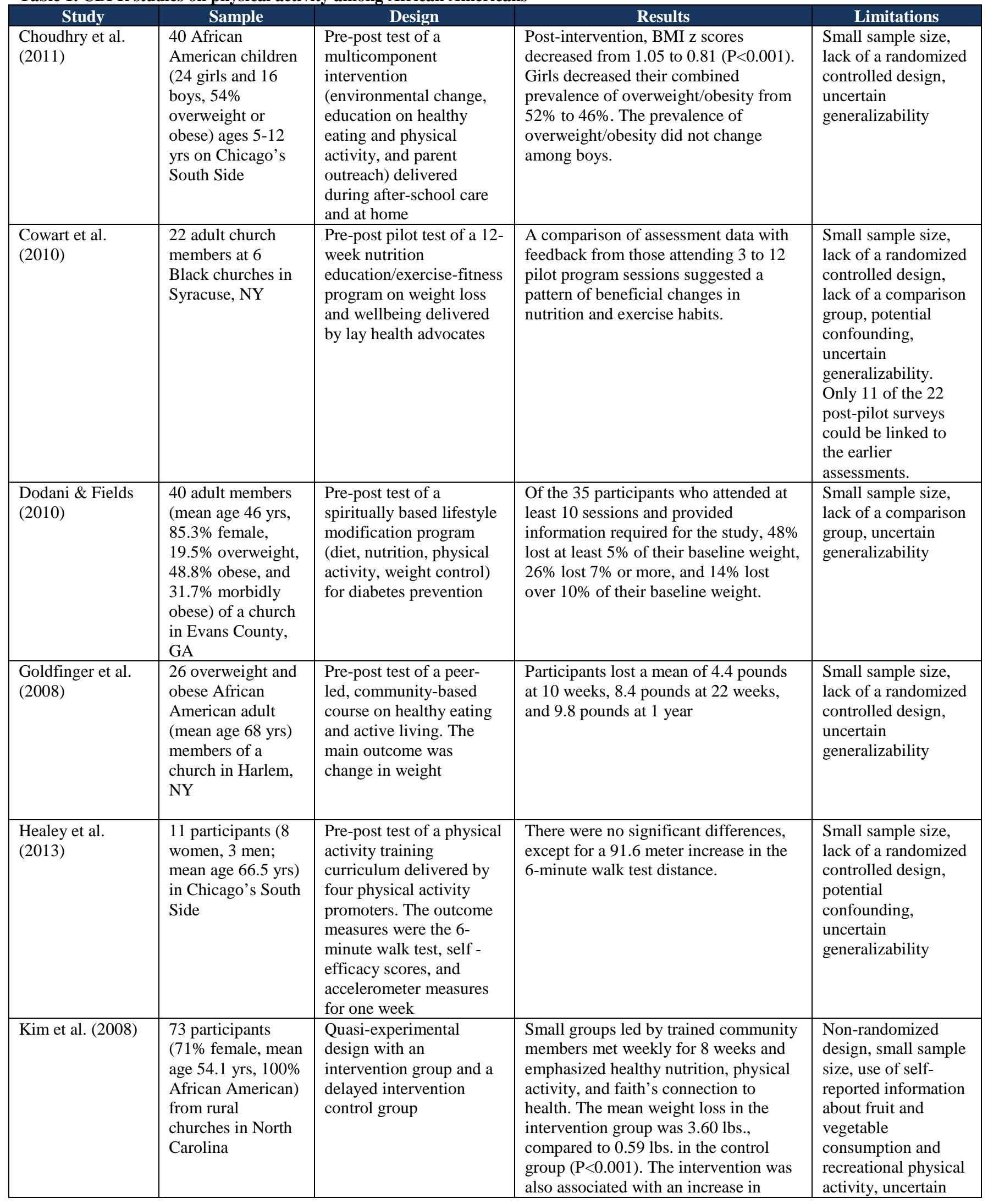




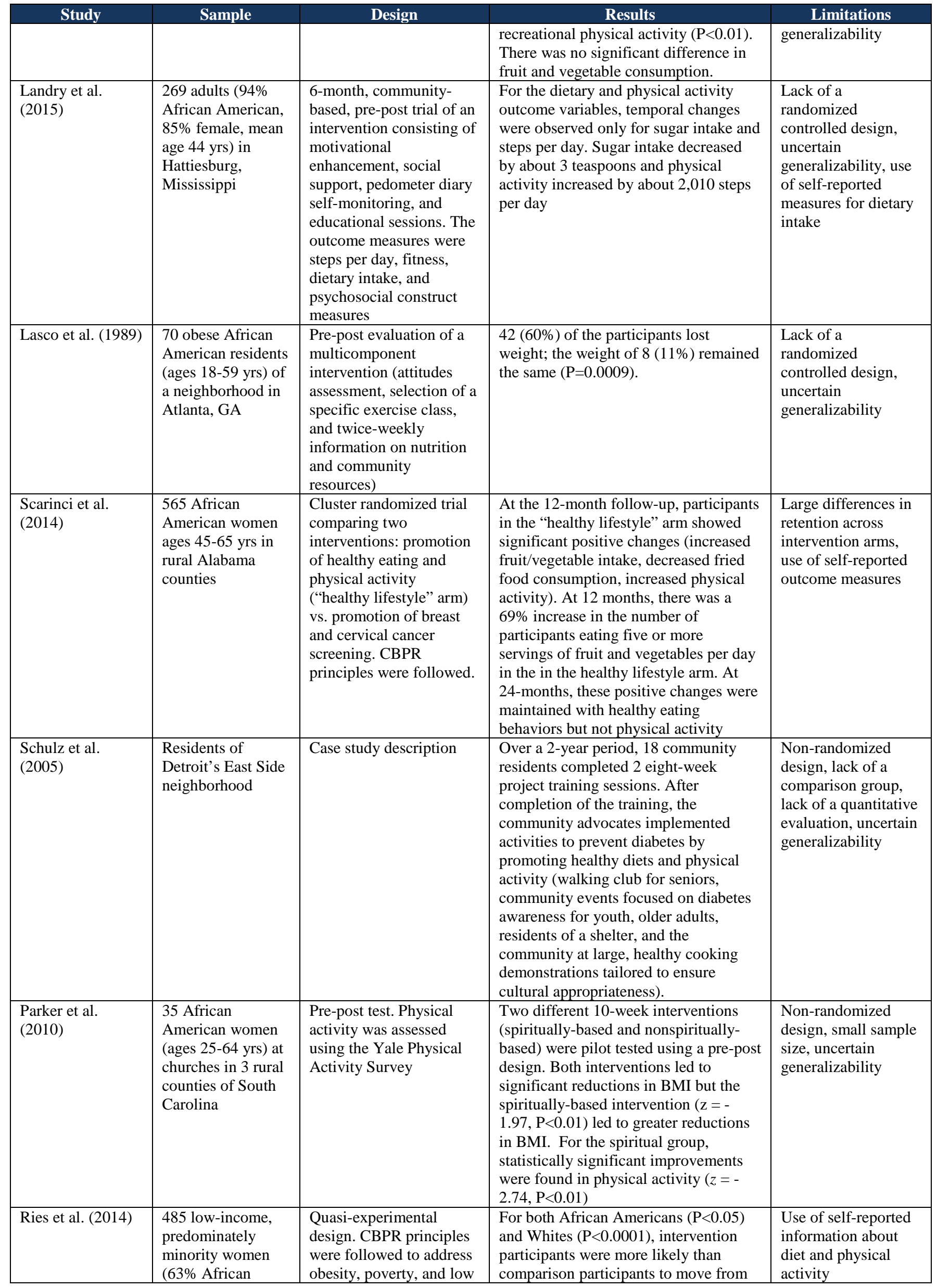




\begin{tabular}{|c|c|c|c|c|}
\hline Study & Sample & Design & Results & Limitations \\
\hline $\begin{array}{l}\text { Wilcox et al. } \\
\text { (2013) }\end{array}$ & $\begin{array}{l}\text { 1,257 participants } \\
\text { (mean ages 54.1 } \\
\text { yrs, 99.4\% African } \\
\text { American, } 27.1 \% \\
\text { overweight, } 61.8 \% \\
\text { obese) who } \\
\text { attended } 74 \\
\text { African Methodist } \\
\text { Episcopal churches } \\
\text { in North Carolina }\end{array}$ & $\begin{array}{l}\text { Cluster randomized } \\
\text { controlled trial of a } \\
\text { CBPR intervention (full- } \\
\text { day committee training, } \\
\text { full-day cook training, } \\
\text { and } 15 \text { months of } \\
\text { mailings and technical } \\
\text { assistance calls) targeting } \\
\text { healthy eating and } \\
\text { physical activity }\end{array}$ & $\begin{array}{l}\text { In intention-to-treat analyses conducted } \\
\text { using analysis of variance, there was a } \\
\text { significant intervention effect in self- } \\
\text { reported leisure-time moderate-to- } \\
\text { vigorous intensity physical activity } \\
\text { ( } \mathrm{P}=0.02) \text { but no effect for dietary } \\
\text { outcomes. Covariance analyses for } \\
\text { participants who completed both pre- } \\
\text { and post-measurements showed an } \\
\text { intervention effect for moderate-to- } \\
\text { vigorous intensity physical activity } \\
(\mathrm{P}=0.03) \text { and self-reported fruit and } \\
\text { vegetable consumption }(\mathrm{P}=0.03) \text {. }\end{array}$ & $\begin{array}{l}\text { High attrition, use of } \\
\text { self-reported } \\
\text { information about } \\
\text { physical activity and } \\
\text { diet }\end{array}$ \\
\hline $\begin{array}{l}\text { Woods et al. } \\
\text { (2013) }\end{array}$ & $\begin{array}{l}106 \text { adults (73\% } \\
\text { female, } 90 \% \\
\text { African American, } \\
80 \% \text { some college } \\
\text { or above) from five } \\
\text { churches (3 } \\
\text { intervention, } 2 \\
\text { control) in } \\
\text { Colorado }\end{array}$ & $\begin{array}{l}\text { Cluster randomized trial } \\
\text { of diet, nutrition, an } \\
\text { physical activity } \\
\text { intervention (small group } \\
\text { educational sessions, } \\
\text { demonstrations of healthy } \\
\text { food preparation, } \\
\text { physical activities) } \\
\text { developed using CBPR } \\
\text { principles }\end{array}$ & $\begin{array}{l}\text { At } 2 \text {-months follow-up, the intervention } \\
\text { group showed greater decreases in } \\
\text { weight }(\mathrm{P}<0.02) \text {, } \mathrm{BMI}(\mathrm{P}<0.05) \text {, and } \\
\text { percent body fat }(\mathrm{P}<0.03) \text { than the } \\
\text { control groups. There was also an } \\
\text { increase in physical fitness }(\mathrm{P}<0.10) \text {. }\end{array}$ & $\begin{array}{l}\text { Limited number of } \\
\text { male participants, } \\
\text { uncertain } \\
\text { generalizability }\end{array}$ \\
\hline
\end{tabular}

A coalition of community and academic leaders conducted a pre-post design, pilot study of a peer-led, community-based course on healthy eating and active living (Goldfinger, J, et al. 2008). The participants were 26 overweight and obese African American adult members of a church in Harlem, NY. Participants lost a mean of 4.4 pounds at 10 weeks, 8.4 pounds at 22 weeks, and 9.8 pounds at 1 year.

Healey et al. (2013) conducted a pre-post test of a physical activity training curriculum delivered by four physical activity promoters. The 11 participants (8 women, 3 men; mean age 66.5 yrs) lived in Chicago's South Side. The outcome measures were the 6-minute walk test, selfefficacy scores, and accelerometer measures at one week.
There were no significant differences except for a 91.6meter increase in the 6-minute walking distance.

Kim et al. (2008) conducted a study of a faith-based weight loss intervention. With an intervention group and a delayedintervention control group, a quasi-experimental design was used. The 73 participants ( $71 \%$ female mean age 54.1 years, $100 \%$ African American) were from rural churches in North Carolina. Small groups led by trained community members met weekly for 8 weeks. The community members emphasized physical activity, healthy nutrition, and the connection of faith to health. The mean weight loss in the intervention group was $3.60 \mathrm{lbs}$. relative to $0.59 \mathrm{lbs}$. in the control group. 
Landry et al. (2015) completed a 6-month, communitybased, pre-post trial of an intervention consisting of motivational enhancement, social support, pedometer diary self-monitoring, and educational sessions. The participants were 269 adults (94\% African American, 85\% female, mean age 44 years) in Hattiesburg, Mississippi. The outcome measures were steps per day, fitness, dietary intake, and psychosocial construct measures. For the physical activity and dietary outcome variables, there were temporal changes observed only for steps per day and sugar intake. Sugar intake decreased by about 3 teaspoons and physical activity increased by approximately 2,010 steps per day.

Using a pre-post design, Lasco et al. (1989) evaluated a community-led multicomponent intervention that consisted of an attitudes assessment, selection of a specific exercise class, and twice-weekly information on nutrition and community resources. The participants were 70 obese African American residents of a neighborhood in Atlanta, Georgia, between the ages of 18 and 59 years. During the intervention, 42 (60\%) of the participants lost weight; the weight of $8(11 \%)$ remained the same $(\mathrm{P}=0.0009)$.

Scarinci et al. (2014) conducted a community-based, cluster-randomized trial comparing two interventions: 1) promotion of physical activity and healthy eating ("healthy lifestyle” arm), and 2) promotion of breast and cervical cancer screening. CBPR principles were followed in planning and accomplishing the study. The participants were 565 African American women of ages 45-65 years in rural counties in Alabama. At the 12-month follow-up, participants in the "healthy lifestyle" arm showed significant positive changes (increased physical activity, increased fruit/vegetable intake, decreased fried food consumption). At 24-months, these positive changes were maintained for healthy eating behaviors but not for physical activity.

Schulz et al. (2005) conducted a CBPR project on diabetes prevention among residents of Detroit's East Side neighborhood. Over a 2-year period, 18 community residents completed 2 eight-week project training sessions. After completion of the training, the community advocates implemented activities to prevent diabetes by promoting physical activity and healthy diets (a walking club for seniors; community events focused on diabetes awareness for youth, older adults, residents of a shelter, and the community at large; and healthy cooking demonstrations tailored to ensure cultural appropriateness).

In three rural counties in South Carolina, Parker et al. (2010) conducted a church-based weight loss intervention among African American women. The study was developed with community involvement. The 35 participants, between the ages of 25 and 64 years, were not pregnant or breastfeeding. Two 10-week interventions (spiritually-based and non-spiritually-based) were pilot tested using a pre-post design. Physical activity was assessed using the Yale Physical Activity Survey. Both interventions led to significant reductions in BMI but the spiritually-based intervention ( $\mathrm{z}=-1.97, \mathrm{P}<0.01$ ) led to greater reductions.
For the spiritually-based group, significant improvements were found in physical activity $(z=-2.74, \mathrm{P}<0.01)$

In rural North Carolina counties, Ries et al. (2014) conducted a project with a quasi-experimental design. The participants were 485 low-income, predominately minority women (63\% African American) with a mean age of 47.5 years. The curriculum for the bi-weekly group meetings held over a 6-month period addressed physical activity, healthy eating, weight control, stress management, education, and job skills. For both African Americans $(\mathrm{P}<0.05)$ and Whites $(\mathrm{P}<0.0001)$, intervention participants were more likely than comparison participants to move from contemplation to action/maintenance for the goal of increasing physical activity. For all participants, progression in stages of change mediated the intervention effect on physical activity, but not fruit and vegetable intake. Intervention group participants engaged in more minutes of physical activity per week (138 minutes) than comparison participants (86 minutes, $\mathrm{P} \leq 0.05$ ).

In 74 African Methodist Episcopal churches in North Carolina, Wilcox et al. (2013) conducted a clusterrandomized controlled trial of an intervention (full-day committee training, full-day cook training, and 15 months of mailings and technical assistance calls) targeting physical activity and healthy eating. The churches were randomized to immediate or delayed intervention. The 1,257 participants (mean age 54.1 years, 99.4\% African American, 27.1\% overweight, $61.8 \%$ obese) had a high attrition. In intentionto-treat analyses accomplished by use of analysis of variance, there was an intervention effect in self-reported, leisure-time moderate-to-vigorous intensity physical activity (MVPA) $(\mathrm{P}=0.02)$ but no effect on dietary outcomes. Covariance analyses for participants who completed preand post-measurements showed an intervention effect for MVPA ( $\mathrm{P}=0.03)$ and self-reported fruit and vegetable consumption $(\mathrm{P}=0.03)$.

With CBPR principles, Woods et al. (2013) conducted a cluster-randomized trial of physical activity, diet, and nutrition interventions (small group educational sessions, demonstrations of healthy food preparation, and physical activities). The 106 adult participants (73\% female, 90\% African American, 80\% with some college or above) were from five churches (3 intervention, 2 control) in Colorado. At 2-months follow-up, the intervention group showed greater decreases in weight $(\mathrm{P}<0.02)$, BMI $(\mathrm{P}<0.05)$, and $\%$ body fat $(\mathrm{P}<0.03)$ than the control groups. There was an increase in physical fitness $(\mathrm{P}<0.10)$.

Zoellner et al. (2007) conducted a quasi-experimental study to evaluate a 6-month intervention focused on promoting physical activity and health through walking teams led by coaches, self-monitoring, and monthly 1-hour educational sessions. The participants were 83 rural residents in Hollandale, Mississippi (99\% African American, 97\% women). There were improvements in waist circumference (-1.4 inches), systolic blood pressure $(-4.3 \mathrm{mmHg})$, and HDL-cholesterol $(+7.9 \mathrm{mg} / \mathrm{dL}) \quad(\mathrm{p}<0.001)$. Self-reported 
walking per day was 44.8 (SD+52.2) minutes at enrollment and $65.9\left(\mathrm{SD}^{+} 89.7\right)$ minutes at 6 months $(\mathrm{P}=0.154)$.

\section{DISCUSSION}

The conclusions of this systematic review show that mixed results have been obtained in CBPR studies related to promotion of physical activity in African American communities, but that modest increases in activity have often been observed. To address health disparities, additional CBPR studies and faith-based interventions are needed to identify optimal approaches for promoting physical activity in African American communities in rural and urban locations to address health disparities. In particular, there is a need for community-engaged studies that have an adequate sample size and a rigorous design (e.g., those with a quasi-experimental or a randomized controlled design), and which overcome limitations of previous studies. These are needed especially in states like Georgia that have substantial health disparities among children, adolescents, and adults.

The prevalence of low physical activity and obesity is a serious threat to the health of African Americans (and members of other racial and ethnic groups) because of the increased risk of cancer of the breast, colon, and other sites; diabetes; cardiovascular diseases; arthritis; sleep apnea; premature mortality; and other adverse health consequences (Dietz, W. 2015; Kumanyika, S, et al. 2014). Physical activity, nutrition, and energy balance are determinants of weight loss and maintenance of healthy weight (Sallis, J \& Glanz, K. 2009).

Public health recommendations emphasize a lifestyle approach to increasing physical activity that includes brisk walking, climbing stairs, doing house work and yard work, and engaging in recreational activities (Dietz, W. 2015). Among persons living with chronic illness, physical activity and maintaining a healthy body weight can reduce the risk of disease progression or recurrence and improve quality of life (Thompson, H, et al. 2012).

Encouraging physical activity among middle-aged and older persons is essential, as they may suffer from one or more chronic illnesses and are at risk of declining physical fitness or unintended weight gain. The 2008 Physical Activity Guidelines for Americans emphasize that all adults should avoid inactivity (HHHs, 2008). Some physical activity is better than none, and adults who participate in any amount of physical activity gain some health benefits. For substantial health benefits, adults should do at least 150 minutes a week of moderate-intensity or 75 minutes a week of vigorous-intensity aerobic physical activity, or an equivalent combination of moderate- and vigorous-intensity aerobic activity. Such activity should be performed in episodes of at least 10 minutes and, preferably, spread throughout the week. Additional guidelines are offered for school children and adolescents (HHS, 2008).

As a collaborative approach, CBPR equitably involves all partners in the research process. These partnerships are often between academic and community organizations and have the goal of increasing the value of the research product for all partners (Corbie-Smith, G, et al. 2011; Smith, S, et al. 2015). CBPR is linked to other social justice-informed approaches to research that attempt to empower communities to address the root causes of inequality and identify their own problems and appropriate solutions (Campbell, M, et al. 2007). The CBPR approach strives to acknowledge and implement the participants' needs, behaviors, and beliefs concerning their well-being (CorbieSmith, G, et al. 2011; Smith, S, et al. 2015). It takes into account the strengths and insights that community and academic partners bring to framing health problems and developing solutions. Many of the studies identified in this review show that community members are often interested in being involved in CBPR and in helping to ensure that the physical activity interventions developed are tailored to the needs of their community.

Numerous faith organizations and institutions are addressing the obesity epidemic and encouraging physical activity at the local level. In the United States, the Black church has long played an important role in addressing social and economic injustices (Campbell, M, et al. 2007). Poverty, lack of safe resources and facilities to exercise, and other injustices are part of the contextual factors that contribute to high obesity rates in the African American community (Gordon-Larsen, P, et al. 2006). Faith organizations at the local, regional, and national level are addressing health disparities related to physical inactivity, over-weight, and obesity among African Americans and other at-risk populations.

\section{CONCLUSIONS}

Additional CBPR studies and faith-based interventions are needed to identify effective ways to promote physical activity in African American communities and to address health disparities. Of particular interest are communityengaged studies that have an adequate sample size and a rigorous design, and which overcome limitations of previous studies, especially in states such as Georgia that have substantial health disparities. In this review, relatively few studies involving African American youth were identified. Additional CBPR studies are needed that involve the participation of adolescents.

\section{Acknowledgements}

This work was funded by the National Cancer Institute (R01CA166785).

\section{References}

Barr-Anderson D, Singleton C, Cotwright C, et al. Outside-ofschool time obesity prevention and treatment interventions in African American youth. Obesity Reviews2014;15(Suppl 4):26-45.

Berkley-Patton J, Moore E, Berman M, et al. Assessment of HIV-related stigma in a US faith-based HIV education and testing intervention. J Int AIDS Soc 2013;16(Suppl 2):18644

Campbell MK, Hudson MA, Resnicow K, et al. Church-base health promotion interventions: evidence and lessons learned. Ann Rev Public Health 2007;28:213-234.

Choudhry S, McClinton-Powell L, Solomon M, et al. Power-up: a collaborative after-school program to prevent obesity in 
African American children. Prog Community Health Partnersh 2011;5:363-373.

Corbie-Smith G, Adimora A, Youmans S, et al. Project GRACE: a staged approach to development of a community-academic partnership to address HIV in rural African American communities. Health Promot Pract 2011;12:293-302.

Cowart L, Biro D, Wasserman T, Stein R, Reider L, Brown, B. Designing and pilot-testing a church-based community program to reduce obesity among African Americans. ABNF J 2010:21:4-10.

Dietz WH. The response of the US Centers for Disease Control and Prevention to the obesity epidemic. Annu Rev Public Health 2015;36:575-596.

Dodani S, Fields J. Implementation of the Fit Body and Soul, a church-based life style program for diabetes prevention in high-risk African Americans. A feasibility study. Diabetes Educ 2010;36:465-472.

Goldfinger J, Arniella G, Wylie-Rosett J, Horowitz C. Project HEAL: peer education leads to weight loss in Harlem. J Health Care Poor Underserved 2008;19:180-192.

Gordon-Larsen P, Nelson M, Page P, Popkin B. Inequality in the built environment underlies key health disparities in physical activity and obesity. Pediatrics 2006;117:417-424.

Healey WE, Reed M, Huber G. Creating a community-physical therapy partnership to increase physical activity in urban African-American adults. Prog Comm Health Partnersh 2013;7:255-262.

HHS 2008 Physical Activity Guidelines for Americans http://health.gov/paguidelines/

Kim K, Linnan L, Campbell M, et al. The WORD (Wholeness, Oneness, Righteousness, Deliverance): a faith-based weightloss program utilizing a community-based participatory research approach. Health Educ Behav 2008;35:634-650.

Kong L, Tussing-Humphreys, Odoms-Young A, et al. Systematic review of behavioural interventions with culturally adapted strategies to improve diet and weight outcomes in African American women. Obes Rev 2014;15(Suppl 4):62-92.

Kumanyika S, Whitt-Glover M, Haire-Joshu D. What works for obesity prevention and treatment in black Americans? Research directions. Obes Rev 2014;15(Suppl 4):204-212.

Landry A, Thomson J, Madson M, et al. Psychosocial constructs and postintervention changes in physical activity and dietary outcomes in a lifestyle intervention, Hub City Steps, 2010. Prev Chronic Dis 2015;12:140525. www.cdc.gov/pcd/issues/2015/14_0525.htm Accessed on January 24, 2016.

Lasco R, Curry R, Dickson V, et al. Participation rates, weight loss, and blood pressure changes among obese women in a nutrition-exercise program. Public Health Rep 1989;104:640646.

Lemacks J, Wells B, Ilich J, Ralston P. Interventions for improving nutrition and physical activity behaviors in adults African American populations: a systematic review, January 2000 through December 2011. Prev Chronic Dis 2013;10:E99. http://www.cdc.gov/pcd/issues/2013/12_0256.htm Accessed on January 24, 2016.
Nader P, Bradley R, Houts R, et al. Moderate-to-vigorous physical activity from ages 9 to 25 years. JAMA 2008;300:295-305.

Newton R Jr, Griffith D, Kearney W, Bennett G. A systematic review of weight loss, physical activity and dietary interventions involving African American men. Obesity Reviews 2014;15(Suppl 4):93-106.

Ogden C, Carroll M, Curtin L, et al. Prevalence of high body mass index in US children and adolescents, 2007-2008. JAMA 2010;303:242-249.

Parker V, Coles C, Logan BN, Davis L. The LIFE Project: a community-based weight loss intervention program for rural African American women. Fam Comm Health 2010:33:133143.

Ries AV, Blackman LT, Page RA, Gizlice Z, Benedict S, Barnes K,..., Carter-Edwards L. Goal setting for health behavior change: evidence from an obesity intervention for low-income women. Rural Remote Health 2014;14:1-14.

Sallis J, Glanz K. Physical activity and food environments: solutions to the obesity epidemic. Milbank Q 2009;87:123154.

Sallis J, Cervero R, Ascher W, et al. An ecological approach to creating active living communities. Annu Rev Public Health 2006;27:297-322.

Scarinci I, Moore A, Wynn-Wallace T, et al. A communitybased, culturally relevant intervention to promote healthy eating and physical activity among middle-aged African American women in rural Alabama: findings from a group randomized controlled trial. Prev Med 2014;69:13-20.

Schulz A, Zenk S, Odoms-Young A, et al. Healthy eating and exercising to reduce diabetes: exploring the potential of social determinants of health frameworks within the context of community-based participatory diabetes prevention. Am J Public Health 2005;95:645-651.

Smith S, Whitehead M, Sheats J, et al. Community-based participatory research principles for the African American community. J Ga Public Health Assoc 2015;5:52-56. http://www.rrh.org.au

Thompson HJ, Sedlacek SM, Paul D, et al. Effect of dietary patterns differing in carbohydrate and fat content on blood lipid and glucose profiles based on weight-loss success of breast cancer survivors. Breast Cancer Res 2012; 14:R1. http://dx.doi.org/10.1186/bcr3082

U.S. Department of Health and Human Services: ObjectivePhysical Activity. http://www.healthypeople.gov/2020/topicsobjectives/topic/physical-activity Assessed on January 24, 2016.

Wilcox S, Parrot A, Baruth M, et al. The Faith, Activity, and Nutrition Program. A randomized controlled trial in AfricanAmerican churches. Am J Prev Med 2013;44:122-131.

Woods G, Levinson A, Jones G, et al. The Living Well By Faith Health and Wellness Program for African Americans: an exemplar of community-based participatory research. Ethn Dis 2013;23:223-229.

Zoellner J, Connell C, Santell R, et al. Fit for Life Steps: results of a community walking intervention in the rural Mississippi Delta. Prog Comm Health Partnersh 2007;1:49-60. 